\title{
Human resource risk management in organization: methodological aspect
}

\author{
Alexandra Mitrofanova \\ State University of Management \\ Moscow, Russia \\ alexamitr@gmail.com \\ Valeriya Konovalova \\ State University of Management \\ Moscow, Russia \\ konovalova_v@mail.ru
}

\author{
Elena Mitrofanova \\ State University of Management \\ Moscow, Russia \\ elmitr@mail.ru \\ Rafik Ashurbekov \\ State University of Management \\ Moscow, Russia \\ rafash@mail.ru
}

\author{
Konstantin Trubitsyn \\ Samara State Technical University \\ Samara, Russia \\ trubitsyn.kv@samgtu.ru
}

\begin{abstract}
The complexity, dynamism and uncertainty of the socioeconomic status of both Russian and global economies generally form a significant number of risks that threaten the effective functioning and development of organizations. Moreover, the urgency of these problems is increasing in the conditions of economic stabilization and the outlook for development, when the degree of certainty and predictability of external factors is increasing, as well as the relative influence of internal organizational factors, among which the most important factors are related to the quality of personnel and the effectiveness of the personnel management system of the organization. Exactly these factors in modern conditions predetermine the success of achieving the strategic goals of the organization, but at the same time determine the emergence of human resources risks, which, in the opinion of experts, is defining the form of risk in the organization. The urgency of this problem has caused the need to develop the presented methodology for managing human resources risks. A distinctive feature of this methodology is the focus on prophylaxis and prevention of human resources risks. The methodology integrates various aspects of human resources risks management: types, levels, the significance, profiles of human resources risks, expected losses from risks, actions of human resources risk management. The methodology includes 5 stages: preparation, analysis, planning, organizing, control.
\end{abstract}

Keywords- human resources risk, personnel management, the sphere of risk occurrence, risk object, source of risk, damage to risk, methodology of HR risk management.

\section{INTRODUCTION}

Awareness of the importance of risk management has come in the Russian business. Over the past 3 years, the demand for specialists in this field has increased almost 7 times.

According to a study by the KPMG International Audit Company, participants in the survey from Russia and Kazakhstan considered the risks of personnel as the most dangerous risks to business (43\%) [1].

According to the international rating of Ernst \& Young, human resources (HR) risks are among the ten most significant risks, occupying the 5th place among them, gaining three points within the last 3 years. Experts believe that the reasons for this is that the personnel in Russian business is simply a more clear source of risk than others, sometimes even more dangerous. Indeed, comparing the threat to get under the close scrutiny of controlling bodies and to become the object of unfriendly absorption, the dangers associated with staff look more predictable. However, according to the same research conducted by KPMG, indicators of predictability compare unfavourably, for example, with financial risks [9].

In the list of risks for managers from Asia, Australia, Western Europe and North America financial, market, credit, currency and legislative risks appear to be more valuable. Human resourses risks are only in the 6th place.

Experts explain the choice of Russian experts by the fact that directly or indirectly the cause of the remaining risks is also people. Frequently to predict their behaviour is much more difficult than at the same time to predict the exchange 
rate. The "human factor" that was not fulfilled in time is the reason for the leadership to be blamed for the failure of the deadlines and the implementation of projects

The above-stated facts explains the need to manage HR risks, including the development of methods for managing these risks in organizations.

\section{RESEARCH METHODS}

The researchers used the following methodology:

- a literature review of risk management and HR risk management;

- consolidating these into a methodology of HR risk management;

- $\quad$ results of the HR risks evaluation according to developed methodology in several Russian consulting companies.

\section{LITERATURE REVIEW}

Studying various authors and researchers, approaching to the content of the HR risk management process, shows that the most of authors equally approach consideration of risks management process content [5, 10, 12]. First of all, it concerns the sequence and the list of management stages. At the same time, any author does not define the full list of risk management functional tasks [7, 11]. Only in 1 case from 8 (that makes 12\%), HR risk management is connected with the risk management strategy (but not with the company strategy in general) and that only after determination of the HR risks level. An essential shortcoming is also the fact that management process is not considered by authors neither in a section of management levels, nor in a section of management subjects $[3,4,8]$.

Thus, the research of the existing methods of HR risk management allows one to make several essential conclusions:

- $\quad$ authors have no principal differences on the content of HR risk management methods while extent of their specification is various $[13,14]$.

- $\quad$ offered HR risk management methods are usually not connected with the risk management strategy in the organization which in most cases is absent $[6,15]$.

- there is no reasonable choice of HR risk management methods depending on types of risk and levels of management [17].

These conclusions became the basis of developing HR risk management methodology.

\section{METHODOLOGY OF HR RISK MANAGEMENT}

The methodology of HR risk management proposed by the authors of the article in the work with the personnel of the organization has a distinctive feature focus on prophylaxis and prevention of HR risks [2].
The proposed methodology for managing HR risks includes the following steps:

\section{A. $\quad$ Stage 1 - Preparation}

At this stage, the following actions are implemented:

1) Setting the objectives of HR risk management.

The objectives of HR risk management in the work with the personnel of the organization are formulated on the basis of a generalization of the risk spectrum of the personnel management system, sectoral and regional staff characteristics.

\section{2) Formation of the HR Risk Management Team}

This step assumes creation in a structure of the enterprise a site which is engaged in management of HR risks and realization of actions for their decrease.

$$
\text { B. } \quad \text { Stage } 2 \text { - Analysis }
$$

At this stage, the following actions are implemented:

\section{1) Qualitative analysis of $\mathrm{HR}$ risks}

The goal of qualitative analysis is to identify possible types of HR risks, as well as to identify factors that affect the level of HR risks in the organization.

a) Monitoring of external and internal factors affecting the HR risks of the organization

Sources of information on external factors that affect the organization's HR risks are: magazines and newspapers; business reports; books; professional meetings; industry conferences; employees of the enterprise; suppliers; customers; information agencies; computer information networks, etc.

Identification of internal factors of HR risks begins with the collection of initial information, which characterizes the riskiness of both the personnel management system of the organization and the personnel of the organization from the following sources of information: intra-organizational regulatory documentation (staffing table, job descriptions, provisions on divisions, etc.); expert assessments; the results of surveys (observations, surveys, questionnaires).

To establish the level of uncertainty in the field of personnel management, the information obtained is evaluated according to the criteria of completeness, reliability, authenticity and realism of data presentation.

The result of identifying $\mathrm{HR}$ risk factors in the HR management system is the formulation of a basic set of HR risks of the organization.

At the heart of the formation of the basic set of HR risks, there is the division of HR risks into two groups: the risks of the personnel management system and the personnel risks.

The risks of the personnel management system are differentiated by the subsystems of the personnel management system: 
- risks associated with the planning and marketing of personnel, including:

- lack of allocation of posts, from which can come the most dangerous threats of information, property, intellectual and other security;

- ineffective (or lack of) determination of the required number of personnel demanded to achieve the company's goals and the qualitative performance of the assigned scope of work, taking into account the criteria of personnel security;

- non-optimal quantitative composition; of staff;

- balanced gender, age and educational groups

- low qualification level and quality of intellectual potential of the organization;

- lack of monitoring of threats to the vital interests of the organization, aimed to ensure human resources security;

- irrational costs for managing the development and safety of personnel, etc.;

- risks related to labour relations, including:

- presence of conflicts, labour disputes, caused by the conflict of interests of employees and the employer;

- lack of staffs' attitudes to a conscious understanding of the need for loyal behaviour towards their employer as one of the main conditions for professional development and the preservation of the workplace;

- unfavourable socio-psychological climate in the team;

- the unformed honesty policy towards clients, employees and the employer;

- lack of measures to identify, prevent and suppress undesirable actions by employees that may cause damage to the interests of the organization;

- lack of control over compliance with the rules for ensuring the safety of the employee and the employer;

- lack of regulation of norms and rules for the resolution of labour conflicts and disputes, etc.;

- risks of conditions and labour protection, including:

- lack of measures for preservation and maintenance of the physical and psychological health of staff;

- ineffective socio-economic working conditions;

- unfavourable psycho-physiological and sanitary-hygienic working conditions;
- inefficient organization of labour of personnel;

- irrational modes of work and leisure time, etc.;

- risks of staff motivation, including:

- lack of a staff motivation program;

- lack of a liability system;

- leaving of "narrow" specialists;

- leaving of senior management;

- lack of activities aimed to motivate the loyalty of employees to the organization;

- lack of stable economic and socio-economic motivation of the most valuable employees, which forces them to refuse any proposals for the change of employer;

- lack of effective motivation for employees to comply with the current rules for ensuring information, property and personal safety;

- lack of incentive for employees to make proactive proposals to improve the security of the organization;

- lack of incentive to retain staff;

- lack of mechanisms for identifying motives and reasons for the dismissal of valuable employees and the place of their subsequent employment, etc.;

- $\quad$ risks of training and development of staff, including:

- lack of correlation between training and evaluation of results;

- the structure and culture of the organization don't contribute to the realization of the acquired knowledge;

- lack of correlation between training and certification procedure;

- investments related to training don't bring the expected return;

- dismissal of an employee after passing the training program;

- non-compliance of training objectives with the needs of the organization;

- poor quality of education (low qualification of teachers, low quality of training modules, limited set of forms of training);

- inadequate ideas of managers about the opportunities and results of training programs, etc.;

- $\quad$ risks of business evaluation of personnel, including: 
- lack of evaluation of the various forms of showing disloyalty and unreliability of the organization's employees, including the stage of passing the test;

- lack of mechanisms for identifying employees whose professionally important and personal qualities creates the possibility of implementing various security threats (risk groups) on their part;

- different standards for employees performing the same work;

- similarity of beliefs and views as a factor affecting business valuation;

- subjectivity of methods of personnel business evaluation;

- an employee's assessment bases not on the performance, but on personal qualities;

- change of standards during business evaluation;

- use of a narrow range of estimates;

- comparison of employees with each other, rather than with the standards of activity;

- absence of conclusions of business evaluation, management decisions, etc.; including:

- risks of social development of personnel,

- absence of conditions aimed to increase the loyalty of employees;

- lack of additional social guarantees for staff being dismissed and assistance in the further employment;

- the lack of a social package, taking into account the security requirements of the organization and the employee;

- the absence of additional options for the social package for those employees who ensure the social and economic development of the organization, etc.;

- $\quad$ risks of inefficient organizational structure, including:

- unreasonableness of the number of personnel taking into account the development strategy of the organization;

- irrational structure of the organization;

- lack of personnel management services;

- inefficient functional division of liabilities and responsibilities for personnel management;

- duplication of human resources security functions;
- lack of regulation of personnel security functions;

- lack of a clear division of functional responsibilities among departments and officials to ensure personnel security, etc.;

- legal security risks, including:

- lack of control over the employee's compliance with the current labor and civil legislation when performing work duties;

- lack of measures to prevent possible applications to the court and reviewing authorities;

- lack of measures to minimize the liability of the employee and the employer for arising labor disputes;

- absence of local normative acts concerning the provision of personnel security, etc.;

- information security risks, including:

- lack of information and explanatory work with the employees of the organization on the rules for conducting confidential business negotiations, communicating with clients, tactics of behavior when trying to recruit and blackmail, ensuring information security of the employer during working and non-working hours;

- untimely and high-quality provision with complete and reliable information required for the performance of labor duties, etc.

Personnel risks arise due to demonstrations of professional, business and personal qualities of the personnel of the enterprise.

In turn, the personnel risks include the following types:

- biological risks (age, level of health, psychophysiological features, abilities);

- socio-psychological risks (demotivation, character accentuation, loyalty, social roles, interpersonal conflicts);

- moral risks (beliefs, beliefs, values, norms, culture);

- intellectual risks (level of intelligence, education);

- economic risks (creativity, professional potential, competencies, qualifications, working capacity, work experience);

- risks of unreliability (short-sightedness, negligence, fear of blackmail, sudden deterioration or improvement of financial position, social status, vanity, desire to retain a position, dependence on something or anyone, intrigue, compromising circle of communication, big debt, easy suggestibility, credulity, lying, having a criminal record, greed, touchiness, 
vindictiveness, meanness, instability to stress, loneliness, secrecy).

\section{b) Identification of $\mathrm{HR}$ risks}

Identification of $\mathrm{HR}$ risks is the process of detecting and establishing quantitative, temporal, spatial and other characteristics necessary and sufficient for the development of preventive and operational measures aimed to ensure quality of HR risk management. In the process of identification, there is determined the probability of manifestation, spatial localization, possible damage and other parameters necessary for solving a particular problem.

The difficulty in identifying HR risks is related to the fact that it is quite difficult to single out the "HR risks" as they are closely related to other types of risks and there is a risk of losing the goal of managing HR risks in the organization [16].

\section{2) Quantitative analysis of HR risks}

The goal of qualitative analysis is to identify possible types of HR risks as well as to identify factors that affect the level of HR risks in the organization.

\section{a) Formalization of $\mathrm{HR}$ risks}

The meaning of the formalization of HR risks is to assess all $\mathrm{HR}$ risks of the organization that are relevant at the given moment and to rank them according to the degree of influence on the personnel security of the organization. For this purpose it is expedient to use the method of peer review.

According to the Harrington scale, HR risks have the following levels of manifestation:

- minimal - factors that affect the organization's HR risks are practically absent; the probability of negative results - zero;

- $\quad$ small - factors that affect the organization's HR risks are not significant; the likelihood of negative results is negligible;

- medium - HR risks of the organization significantly reduce the effectiveness of personnel management; the likelihood of negative results is substantial;

- high - HR risks of the organization significantly reduce the effectiveness of personnel management; the probability of occurrence of negative events is significant.

- critical - HR risks expose the implementation of the organization's human resources security; the probability of occurrence of negative events is maximal.

As a result of the evaluation expert estimates should be obtained: the level of HR risks; the significance (rating) of the identified factors of HR risks (the profile of HR risks); values of indicators of the state of HR risk factors.

b) Building a HR risk profile of an organization
The profile of HR risks is a characteristic of the risky appearance of the organization in the form of a ranked list of factors of HR risks, taking into account the probability of their occurrence and the extent of possible damage.

\section{c) Deciding whether the risk is acceptable}

The analysis of the profile of HR risks makes it possible to identify factors that have a significant negative impact on the activities of personnel and the entire organization. It is necessary to develop measures to neutralize factors with a view of reducing the level of HR risks of the organization.

\section{C. $\quad$ Stage 3 - Planning}

This stage includes the following actions:

\section{1) Elaboration of a plan of measures to manage HR risks}

An action plan is developed for each identified HR risk and a consolidated plan of activities to manage HR risks in the organization.

The basis for planning activities for managing HR risks is the choice of the method of impact on each identified HR risk in the organization: \[ \quad \text { further study of HR risk, in case of lack of } \]
information;
objective necessity of carrying out of changes;

- management of HR risk, if necessary, actions that reduce the likelihood of risk or reduce its damage;

- avoidance of HR risk, if necessary elimination of its causes without trying to change the situation.

Further, an action plan for managing $\mathrm{HR}$ risks is developed, containing the following information:

- $\quad$ HR risk identification;

- $\quad$ formulation of HR risk;

- description of losses from HR risk;

- description of the HR risk management strategy;

- $\quad$ sequence of actions necessary to implement the HR risk management strategy;

- $\quad$ timing of the implementation of the HR risk management strategy;

- officials responsible for implementing the HR risk management strategy.

\section{2) Development of a budget for HR risk management}

Budgets are being developed to implement the measures in accordance with the developed risk management plan. 
3) Identification of funding sources for human resources management

HR risks can be financed from the owners' own funds, from borrowed sources, through the sale of financial instruments, shared capital, from retained earnings and from the potential savings that will be brought about by the effective management of HR risks as a profit center.

\section{4) Documenting the management of HR risks}

Schedules, orders and other organizational, administrative, instructive documents and other materials are prepared, which should ensure the implementation of the developed risk management plan.

\section{Stage 4 - Organizing}

At this stage, the implementation of the action plan for the management of HR risks of the organization is carried out.

\section{E. Stage 5-Control}

This stage includes the following actions:

1) Assessment of the effectiveness of human resources management

Taking into account the concept of acceptable risk, an assessment of the effectiveness of HR risk management consists in comparing the starting level of HR risk characterizing losses from the implementation of risk events, with its final level characterizing losses after minimizing risk events and the costs of risk management.

\section{2) Operational control over HR risks of the organization}

The following groups of $\mathrm{HR}$ risks control are distinguished:

- $\quad$ monitoring of expected HR risks, those that have only been outlined, but have not yet received their negative development;

- $\quad$ control of the realized HR risks, which have already shown their negative effect, but have not yet managed to cause the organization significant damage;

- control of the HR risks that have already taken place, which have already caused damage to the organization.

\section{3) Revision and updating of the HR risk assessment system}

Given the dependence of the assessment of HR risk on a significant number of variable internal and external factors, its results should be reviewed if the results of such assessment are no longer relevant.

The results of $\mathrm{HR}$ risks evaluation make it possible to develop the following recommendations to neutralize factors with a view of reducing the level of internal HR risks of these organizations:

\section{RESULTS AND DISCUSSION}

The developed methodology of HR risk management has undergone approbation in several consulting companies Analysis of the HR risks profile (Table 1) has shown that the risks of the personnel management system have the most significant negative impact on the activities of personnel and the entire organizations.

TABLE I. Profile of HR risks

\begin{tabular}{|c|c|c|}
\hline № & HR risks & $\begin{array}{l}\text { HR risk } \\
\text { level }\end{array}$ \\
\hline 1. & ineffective HR management system & 0.8 \\
\hline 2. & leaving of "narrow" specialists & 0.76 \\
\hline 3. & unfavorable socio-psychological climate in the team & 0.72 \\
\hline 4. & lack of a staff motivation program & 0.72 \\
\hline 5. & intellectual risks & 0.71 \\
\hline 6. & lack of incentive to retain staff & 0.7 \\
\hline 7. & lack of career progression & 0.7 \\
\hline 8. & $\begin{array}{l}\text { inefficient functional division of liabilities and } \\
\text { responsibilities for personnel management }\end{array}$ & 0.7 \\
\hline 9. & leaving of senior management & 0.68 \\
\hline 10. & \begin{tabular}{|lllll} 
an employee's assessment based not on the \\
performance, but on personal qualities
\end{tabular} & 0.66 \\
\hline 11. & $\begin{array}{l}\text { lack of allocation of posts, from which the most } \\
\text { dangerous threats of information, property, intellectual } \\
\text { and other security can come }\end{array}$ & 0.61 \\
\hline 12. & $\begin{array}{l}\text { lack of activities aimed to motivate the loyalty of } \\
\text { employees to the organization }\end{array}$ & 0.6 \\
\hline 13. & 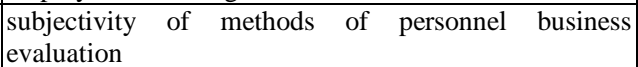 & 0.6 \\
\hline 14. & irrational structure of the organization & 0.6 \\
\hline 15. & dismissal of employees after passing training programs & 0.6 \\
\hline 16. & $\begin{array}{l}\text { inefficient functional division of liabilities and } \\
\text { responsibilities for personnel management }\end{array}$ & 0.6 \\
\hline 17. & risks of unreliability & 0.56 \\
\hline 18. & $\begin{array}{l}\text { non-compliance of training objectives with the needs of } \\
\text { the organization }\end{array}$ & 0.55 \\
\hline 19. & lack of regulation of personnel security functions & 0.54 \\
\hline 20. & unbalanced gender, age and educational groups of staff & 0.52 \\
\hline 21. & $\begin{array}{l}\text { low qualification level and quality of intellectual } \\
\text { potential of the organization }\end{array}$ & 0.52 \\
\hline 22. & $\begin{array}{l}\text { absence of conclusions of business evaluation, } \\
\text { management decisions }\end{array}$ & 0.51 \\
\hline 23. & $\begin{array}{l}\text { absence of conditions aimed to increase the loyalty of } \\
\text { employees }\end{array}$ & 0.51 \\
\hline 24. & $\begin{array}{l}\text { low qualification level and quality of intellectual } \\
\text { potential of the organization }\end{array}$ & 0.51 \\
\hline 25. & $\begin{array}{l}\text { presence of conflicts, labour disputes, caused by the } \\
\text { conflict of interests of employees and the employer }\end{array}$ & 0.49 \\
\hline 26. & $\begin{array}{l}\text { lack of incentive for employees to make proactive } \\
\text { proposals to improve the security of the organization }\end{array}$ & 0.49 \\
\hline 27. & socio-psychological risks & 0.48 \\
\hline 28. & lack of regulation of working hours and overtime work & 0.48 \\
\hline 29. & economic risks & 0.48 \\
\hline 30. & irrational modes of work and leisure time & 0.39 \\
\hline 31. & moral risks & 0.33 \\
\hline 32. & biological risks & 0.24 \\
\hline
\end{tabular}

\section{A. $\quad$ Strategic management level}

- Development of HR policy and HR management strategy, information and explanatory work with the employees of the organization; 
- Increasing in budget for following HR management functions: training and development of staff, staff selection and recruitment, staff motivation and incentive system;

- Improvement of the HR management system including the organizational structure and clear division of functional responsibilities;

- Involvement of line managers in development of strategic and operational decisions.

\section{B. $\quad$ Tactical management level}

- Improvement of HR management methods including staff training and development, staff selection and recruitment, staff motivation;

- $\quad$ Line managers development;

- Organization of corporate events and team building trainings;

- Development of employees' performance evaluation system;

- Strengthening of staff training and development results control.

\section{Operational management level}

- Rationalization of work and leisure time modes depending on the seasonal factor.

- Determination of the required number of personnel depending on the seasonal factor.

- Involvement of line managers in staff selection and recruitment.

Organization of corporate events to generate and maintain favourable social-psychological environment in the team.

\section{CONCLUSION}

Implementation of the proposed methodology for managing HR risks allows:

uninterrupted and sustainable functioning of organizations at the strategic and operational levels;

- achieving the organization's target orientations through early identification and neutralization of external and internal HR risks;
- $\quad$ increasing the trust and loyalty of consumers of the organization's services through the timely identification and elimination of HR risks;

- $\quad$ maximizing the additional profit received as a result of management of HR risks on the basis of rational use of risks;

- effectively redistributing of resources to priority areas of work by eliminating inefficient procedures and projects.

\section{References}

[1] "Risk management of the organization: Integrated model", 2004.

[2] A. Mitrofanova, "The concept of HR risk management in work with personnel of the organization", Kompetentnost', Vol.3, 2013.

[3] A. Levenson, "Harnessing the power of HR analytics", Strategic HR Review, Vol. 4 Issue: 3, pp.28-31, 2005.

[4] A. Lopez-Cabrales, M. Bornay-Barrachina, M. Diaz-Fernandez, "Leadership and dynamic capabilities: the role of HR systems", Personnel Review, Vol. 46 Issue: 2, pp.255-276, 2017.

[5] Becker, Karen \& Smidt, Michelle, "A risk perspective on human resource management: A review and directions for future research", Human Resource Management Review, 26(2), pp. 149-165, 2016.

[6] Becker, Karen \& Smidt, Michelle, "Workforce-related risks in projects with a contingent workforce", International Journal of Project Management, 33(4), pp. 889-900, 2015.

[7] B. Jiang, R.C. Baker, G.V Frazier, "An analysis of job dissatisfaction and turnover to reduce global supply chain risk: Evidence from China", Journal of Operations Management, 27(2), pp.169-184, 2009.

[8] J. Ledwidge, "Corporate social responsibility: the risks and opportunities for HR: Integrating human and social values into the strategic and operational fabric", Human Resource Management International Digest, Vol. 15 Issue: 6, pp.27-30, 2007.

[9] J.Brunold, S. Durst, "Intellectual capital risks and job rotation", Journal of Intellectual Capital, Vol. 13 Issue: 2, pp.178-195. 2012.

[10] J. Bryson, "Managing HRM risk in a merger", Employee Relations, Vol. 25 Issue: 1, pp.14-30, 2003.

[11] M.D. Magau, G. Roodt, , "An evaluation of the Human Capital BRidgeTM Framework", SA Journal of Human Resource Management/SA Tydskrif vir Menslikehulpbronbestuur, 8(1), 2010.

[12] M. Meyer, G. Roodt, M. Robbins, "Human resources risk management: governing people risks for improved performance: Opinion paper. SA Journal of Human Resource Management, 9(1), pp. 1-12, 2011.

[13] C. Paul, L. Mitlacher, Expanding risk management systems: human resources and German banks. Strategic Change, 17, pp. 21-33, 2008.

[14] P. Cheese, "Managing risk and building resilient organisations in a riskier world", Journal of Organizational Effectiveness: People and Performance, Vol. 3 Issue: 3, pp.323-331, 2016.

[15] R. Viitala, S. Kultalahti, H. Kangas, "Does strategic leadership development feature in managers' responses to future HRM challenges?", Leadership \& Organization Development Journal, Vol. 38 Issue: 4, 2017.

[16] M. Sanborn, "Tactics to reduce pharmacy staff turnover and increase job satisfaction", Hospital Pharmacy, 43(8), pp. 670-675, 2008.

[17] W. Cascio, J. Boudreau, "HR strategy: optimizing risks, optimizing rewards", Journal of Organizational Effectiveness: People and Performance, Vol. 1 Issue: 1, pp.77-97, 2014. 